\title{
COVID-19, hydroxychloroquine and sudden cardiac death: implications for clinical practice in patients with rheumatic diseases
}

\author{
Hussain Ahmed Raza ${ }^{1}$ (D) Javeria Tariq ${ }^{1}$ (D) Vikas Agarwal $^{2}$ (D) $\cdot$ Latika Gupta $^{2}$ (D)
}

Received: 27 October 2020 / Accepted: 21 November 2020 / Published online: 1 January 2021

(c) Springer-Verlag GmbH Germany, part of Springer Nature 2021

\begin{abstract}
Sudden cardiac death is commonly seen due to arrhythmias, which is a common cardiac manifestation seen in COVID-19 patients, especially those with underlying cardiovascular disease (CVD). Administration of hydroxychloroquine (HCQ) as a potential treatment option during SARS-CoV-2, initially gained popularity, but later, its safe usage became questionable due to its cardiovascular safety, largely stemming from instances of cardiac arrhythmias in COVID-19. Moreover, in the setting of rheumatic diseases, in which patients are usually on HCQ for their primary disease, there is a need to scale the merits and demerits of HCQ usage for the treatment of COVID-19. In this narrative review, we aim to address the association between usage of HCQ and sudden cardiac death in COVID-19 patients. MEDLINE, EMBASE, ClinicalTrials.gov and SCOPUS databases were used to review articles in English ranging from case reports, case series, letter to editors, systematic reviews, narrative reviews, observational studies and randomized control trials. HCQ is a potential cause of sudden cardiac death in COVID-19 patients. As opposed to the reduction in CVD with HCQ in treatment of systemic lupus erythematous, rheumatoid arthritis, and other rheumatic diseases, safe usage of HCQ in COVID-19 patients is unclear; whereby, it is observed to result in QTc prolongation and Torsades de pointes even in patients with no underlying cardiovascular comorbidity. This is occasionally associated with sudden cardiac death or cardiac arrest; hence, its clinical efficacy needs further investigation by large-scale clinical trials.
\end{abstract}

Keywords COVID-19 Pandemic $\cdot$ Hydroxychloroquine $\cdot$ Antimalarials $\cdot$ Cardiovascular risk

\begin{tabular}{|c|c|c|c|c|}
\hline \multicolumn{3}{|c|}{ Abbreviations } & SCD & Sudden Cardiac Death \\
\hline \multirow{2}{*}{\multicolumn{2}{|c|}{ SARS-CoV-2 }} & Severe acute respiratory syndrome corona- & CVD & Cardiovascular disease \\
\hline & & virus 2 & HTN & Hypertension \\
\hline \multirow{2}{*}{\multicolumn{3}{|c|}{ Hydroxychloroquine }} & MI & Myocardial Infarction \\
\hline & & & HFpEF & Heart failure with preserved ejection \\
\hline \multirow{2}{*}{\multicolumn{3}{|c|}{$\begin{array}{l}\text { Supplementary Information The online version contains } \\
\text { supplementary material available at https://doi.org/10.1007/s0029 } \\
6-020-04759-2 \text {. }\end{array}$}} & CAD & fraction \\
\hline & & & DM & Diabetes Mellitus \\
\hline \multirow{9}{*}{$\square$} & \multirow{2}{*}{\multicolumn{2}{|c|}{$\begin{array}{l}\text { Latika Gupta } \\
\text { drlatikagupta@gmail.com }\end{array}$}} & $\mathrm{CCF}$ & Congestive Cardiac Failure \\
\hline & & & ACE-2 & Angiotensin-Converting Enzyme 2 \\
\hline & \multirow{2}{*}{\multicolumn{2}{|c|}{$\begin{array}{l}\text { Hussain Ahmed Raza } \\
\text { hussain_gorz@outlook.com }\end{array}$}} & RAAS & Renin-Angiotensin-Aldosterone System \\
\hline & & @ outlook.com & AT II & Angiotensin II \\
\hline & \multirow{2}{*}{\multicolumn{2}{|c|}{$\begin{array}{l}\text { Javeria Tariq } \\
\text { javeria.tariq@scholar.aku.edu }\end{array}$}} & RT-PCR & Reverse transcriptase-Polymerase Chain \\
\hline & & & & Reaction \\
\hline & \multirow{3}{*}{\multicolumn{2}{|c|}{$\begin{array}{l}\text { Vikas Agarwal } \\
\text { vikasagr@yahoo.com }\end{array}$}} & iPSCs & Induced pluripotent stem cells \\
\hline & & & TnT & Cardiac troponin $\mathrm{T}$ \\
\hline & & & CRP & C-reactive protein \\
\hline \multirow[t]{2}{*}{1} & \multirow{2}{*}{\multicolumn{2}{|c|}{$\begin{array}{l}\text { Medical College, The Aga Khan University, National } \\
\text { Stadium Road, Karachi 74800, Pakistan }\end{array}$}} & $\mathrm{LDH}$ & Lactate Dehydrogenase \\
\hline & & & ROS & Reactive oxygen species \\
\hline \multirow[t]{2}{*}{2} & \multirow{2}{*}{\multicolumn{2}{|c|}{$\begin{array}{l}\text { Department of Clinical Immunology and Rheumatology, } \\
\text { Sanjay Gandhi Postgraduate Institute of Medical Sciences, }\end{array}$}} & vWF & Von Willebrand Factor \\
\hline & & & $\mathrm{TCZ}$ & Toclizumab \\
\hline
\end{tabular}




$\begin{array}{ll}\text { CQ } & \text { Chloroquine } \\ \text { SLE } & \text { Systemic Lupus Erythematous } \\ \text { RA } & \text { Rheumatoid Arthritis } \\ \text { cGAS } & \text { Cyclic GMP-AMP synthase } \\ \text { FDA } & \text { Food and Drug Administration } \\ \text { EUA } & \text { Emergency Use Authorization } \\ \text { CDC } & \text { Centers for Disease Control and } \\ & \text { Prevention } \\ \text { RCT } & \text { Randomized Control Trial } \\ \text { AZT } & \text { Azithromycin } \\ \text { TdP } & \text { Torsades de pointes } \\ \text { hERG } & \text { Human ether-à-go-go-related gene } \\ \text { DMARDs } & \text { Disease-modifying anti-rheumatic drugs }\end{array}$

\section{Introduction}

The Coronavirus disease 2 (COVID-19) pandemic has led to a disaster like situation, with widespread morbidity and mortality, not only due to the disease but also due to collateral damage to the economy, disrupted logistics of healthcare, and global negative impact on mental health. Despite being nine months into the pandemic and intensive exploration of therapeutic options, there is no successful drug for the condition yet [1]. While hydroxychloroquine (HCQ) seemed to be a promising option in the earlier days of the pandemic, emerging evidence has questioned its utility and also raised certain concerns on the safety of the drug. Most of these pertain to cardiovascular safety of HCQ, largely stemming from instances of cardiac arrhythmias in COVID-19 [2]. This assumes a larger relevance in the setting of rheumatic diseases, where patients are usually on HCQ for their primary disease. Since HCQ levels are likely to remain in the body for long after discontinuation, the events of cardiac toxicity call for re-examining the risk of sudden cardiac death in the event of COVID-19 infection. Furthermore, a recent review concluded that although the role of HCQ for treatment of COVID-19 shall be more clear following ongoing clinical trials, it is necessary to cautiously take into account the risk-benefit ratio before prescribing HCQ for COVID19 , particularly to high-risk populations to prevent adverse drug reactions [3]. Since there are limited data regarding the use of HCQ to treat rheumatic disease patients infected with COVID-19, rheumatologists may need to form appropriate management strategies on a case-by-case basis $[4,5]$. Despite suggestions of severe disease course of COVID-19 infection in patients with RDs, the hospitalization rates and clinical features of such patients are similar to non-rheumatic disease patients $[6,7]$.

The manifestations of COVID-19 are diverse, ranging from anosmia and upper respiratory symptoms to respiratory distress. Existing literature suggests that COVID-19 infection results in new cardiovascular complications or may aggravate underlying cardiovascular disease (CVD), leading to sudden cardiac death (SCD) $[8,9]$. Common cardiac manifestations during severe acute respiratory syndrome coronavirus 2 (SARS-COV2) infection include myocardial infarction, arrhythmia, cardiac arrest, myocarditis, cardiomyopathy, heart failure with preserved ejection fraction (HFpEF), acute cardiac/myocardial injury, cardiogenic shock and venous and arterial thromboembolic complications [10-13]. Patients with a high cardiovascular risk profile are particularly susceptible to the latter complications, and such observations have been made in previous pandemics such as influenza as well [14-17]. SCD is the hardest outcome measure among all cardiovascular events. In this review, we hope to examine the association of COVID-19 with SCD and its intersection with HCQ usage.

\section{Search strategy}

A literature review was conducted in light of the review recommendations by Gasparyan et al. [18]. A search was conducted using the MEDLINE, EMBASE, ClinicalTrials. gov and SCOPUS databases to identify articles in English on the subject. All kinds of articles, ranging from case reports, case series, letter to editors, systematic reviews, narrative reviews, observational studies and randomized control trials published till November 14, 2020 were reviewed. The search terms included: "COVID-19 OR SARS-CoV2 OR SARSCOV-2 OR novel coronavirus OR nCOV", "Cardiac involvement OR Cardiac Injury OR Cardiovascular System OR Cardiovascular Complications OR Cardiovascular manifestations OR Myocardial Infarction OR arrhythmias OR Sudden Cardiac Death", "Hydroxychloroquine OR HCQ" and "Treatment OR therapy OR Pharmacology". Combinations of the above-mentioned terms were used to identify around 1600 articles. All articles were independently reviewed, and relevant information was extracted for this review.

\section{Cardiovascular involvement in COVID-19 patients}

\section{Risk factors}

Increased age ( $>65$ years), male gender and pre-existing comorbidities like hypertension (HTN), diabetes mellitus (DM), coronary artery disease (CAD), and congestive cardiac failure (CCF) are the main risk factors of cardiac involvement during infection with COVID-19 [19-23]. $\mathrm{Wu}$ et al. demonstrated increased mortality in elderly male patients with an underlying history of smoking and hypertension [24]. Studies suggest that pre-existing heart conditions are present in $8-25 \%$ of the infected population, with the disease being more severe in the elderly [25-27]. Furthermore, 
a meta-analysis carried out by $\mathrm{Bo} \mathrm{Li}$ et al. comprising of 1527 patients in China indicated the presence of hypertension, cardiac disease, and diabetes to be $17.1 \%, 16.4 \%$, and $9.7 \%$, respectively, amongst infected patients [28].

The more serious affliction of COVID-19 in those with an underlying CVD has been speculated to be linked to the enhanced interaction of the viral spike protein with the ACE-2 (Angiotensin-Converting Enzyme 2) receptor, which may be overexpressed in this population [17, 29,30]. Therefore, concomitant CVD in elderly patients may make them more susceptible to worsening infection in COVID-19. Despite the initial conundrum resulting from a speculated higher risk of COVID-19 in those on ACEIs (Angiotensinconverting enzyme inhibitors) or ARBs (Angiotensin Receptor blockers) due to a postulated elevation in ACE receptor levels, a recent systematic review consisting of 11 studies with 33,483 patients failed to identify an increased risk of COVID-19 with anti-hypertensives targeting the RAAS. In fact, ACEI/ARB therapy showed a decreased risk of worsening of COVID-19 and, thus, reduced mortality [31]. Moreover, an advisory by the American Heart Association suggested that there is a heightened risk for individuals contracting COVID-19 by visiting their GP for a revised prescription of anti-hypertensives rather than continuing with ACEI [32]. Another retrospective cohort study showed similar findings concluding safe usage of ACEI in hypertensive patients with COVID-19 [33].

\section{Pathogenic mechanisms}

SARS-COV-2 can infect the cardiovascular system both directly and indirectly, considering the pronounced tropism of the virus for heart [34-36]. Several mechanisms underlie the worsening of symptoms in case of cardiac involvement:

\section{ACE-2-mediated direct myocardial injury}

SARS-COV2 gains entry into cells via binding of its spike protein to ACE-2 receptor, which is located on the heart, lungs, intestines and kidneys [17, 37-42]. ACE-2 regulates RAAS (Renin-Angiotensin-Aldosterone System) that is an important control mechanism of blood pressure [29]. This interaction inhibits the conversion of Angiotensin II (AT-II) into Angiotensin 1-7, which normally prevents inflammation, fibrosis and leads to vasodilation, thereby protecting the heart and lung from injury [43]. Hence, a decrease in ACE-2 results in the increased levels of AT-II, which is pro-inflammatory and increases the risk of heart failure [15]. These patients may have a higher mortality rate due to upregulation of ACE-2 receptor expression [39]. Furthermore, the infection is more critical as compared to SARS-COV-1, because SARS-COV-2 has a tenfold greater binding affinity due to its unique structure $[10,15]$. Since greater than $7.5 \%$ of heart cells carry the ACE- 2 receptor-binding domain, the virus directly enters the heart, resulting in cardiotoxicity that eventually leads to acute myocardial injury and chronic heart damage [30, 38, 44]. This phenomenon was confirmed by the presence of viral particles in cardiac tissue found by RTPCR (Reverse transcriptase-Polymerase Chain Reaction) in COVID-19 patients [40, 45].

\section{Viral myocarditis}

Infections by certain viruses like influenza and parvovirus B-19 are known to be some of the most common causes of myocarditis [46, 47]. Autopsy reports of COVID patients show the presence of myocyte necrosis with lymphocytes in vicinity, suggestive of viral myocarditis [48]. SARS-COV-2 seemingly carries the ability to replicate inside cardiomyocytes and pericytes, leading to inflammation [49]. Moreover, interstitial infiltrates have also been seen in non-survivors of COVID-19, further indicative of a virus attack on the myocardium [9]. In line with this, raised levels of cardiac troponin and creatine kinase in COVID patients also indicate the direct destruction of myocytes by the virus, leading on to myocarditis [34]. Further evidence is highlighted by in vitro studies whereby the SARS-Cov2 led to the destruction of contractile function and apoptosis of cardiac myocytes originated from induced pluripotent stem cells (iPSCs) leading to cardiac death within $72 \mathrm{~h} \mathrm{[36].}$

\section{Cytokine storm}

A cytokine storm is central to the immune pathogenesis of COVID-19 patients [50]. A massive release of cytokines consequent to T-cell activation (IL-1, IL-10, IL-12, IL-6, IL-7, IFN- $\gamma$, TNF- $\alpha$, CXCL10, CSF, etc.) may lead to direct myocardial fiber injury [9-11, 29, 41, 46, 51, 52]. Cytokines such as TNF and IL-15 can directly induce myocardial fiber dysfunction, leading to stunning of the myocardium and poor contractile function [53]. Tao Guo et al. demonstrated a positive correlation between cardiac troponin $\mathrm{T}(\mathrm{TnT})$ levels and C-reactive protein (CRP) levels, objectively demonstrating an association of heart injury with inflammation [54]. Additionally, a study by PE et al. showed that IL-6 was also involved in QTc prolongation in COVID-19 patients [55]. Therefore, raised levels of inflammatory markers like CRP, ferritin, IL-6 and Lactate Dehydrogenase (LDH) may associate with elevated markers of myocardial injury like creatine kinase and myoglobin, which on a background of a cytokine storm may be associated with increased fatality $[9,22,25]$.

\section{Hypoxia and myocardial demand-supply mismatch}

Inflammation of alveolar epithelial cells during SARSCOV-2 infection leads to respiratory distress and associated 
impaired ventilation causing hypoxemia (low levels of oxygen in blood [17, 49, 56, 57]. The ensuing hypoxia results in acidosis and production of reactive oxygen species (ROS), which may damage the cell membrane of myocytes [28, 52]. This, in addition to an increased oxygen demand from the myocytes in the face of infection-induced fever and tachycardia, results in an oxygen demand-supply mismatch, which may be contributive towards a Type 2 myocardial infarction $[12,22,25,34,41,58,59]$ Additionally, hypotension in a severe cytokine storm may further accentuate the ischemia due to poor coronary perfusion. Moreover, hypoxemia leads to the increased entry of calcium ions into cells that further aids the apoptotic cascade [28, 52]. These events would be the forerunners to arrhythmia, cardiogenic shock or even SCD [57].

\section{Plaque rupture and coronary thrombosis}

Recent insights suggest activation of the pro-thrombotic cascade as a key event in the pathogenesis of SARS-CoV2mediated organ dysfunction. ACE-2 receptor is also located on the endothelial cells lining the vessels and hence serves as an entry point for the virus which then mediates inflammation (endothelitis) resulting in endothelial dysfunction [60]. This may ultimately lead to thrombogenesis in COVID-19 [61]. It has also been noticed that patients with severe infection had raised serum levels of vWF (Von Willebrand Factor), which mediates adhesion and aggregation of platelets in vessel walls resulting in blockage [62]. Additionally, the cytokine storm in critically ill patients aids the development of a pro-coagulant and pro-thrombotic state, leading to the development of Disseminated Intravascular Coagulation (DIC) [34, 49]. Hence, thrombi in coronary vessels, together with an exaggerated inflammatory response, may contribute to rupture of unstable atherogenic plaques, manifesting as myocardial infarction [40, 44, 58, 59].

\section{Anti-viral therapy-induced}

Several anti-viral therapies have been employed to counter COVID-19 infection; however, some have shown to have damaging side effects on the cardiac system [10, 59]. Chloroquine and HCQ cause prolongation of the QT interval, which increases the risk of torsades de pointes [49] and predisposes to arrhythmia, especially when combined with azithromycin [29]. Other medications like Ritonavir and Ribavirin enhance hyperlipidemia; while, Tocilizumab (TCZ) and Interferon alpha 2B (IFN) result in hypertension all of which may result in cardiac complications [39] (Fig. 1).

\section{Electrolyte imbalances}

Electrolyte imbalances are known to be a common cause of arrhythmias, especially in patients with concomitant CVD [59]. Furthermore, during SARS-COV2 infection, the RAAS

Covid-19, Hydroxychloroquine and Sudden Cardiac Death: Implications for Clinical Practice in Patients with Rheumatic Diseases

HCQ and Covid-19

\section{Positive effects}

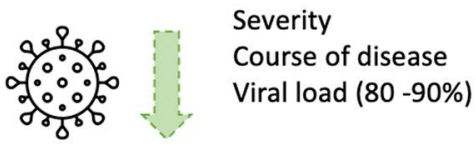

Negative effects

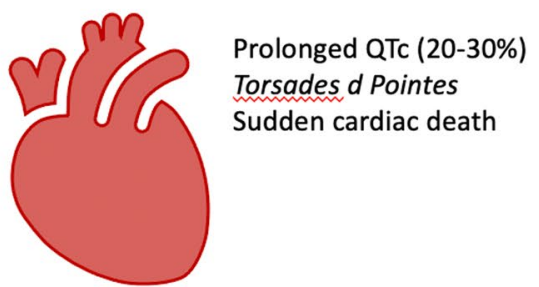

HCQ and Rheumatic diseases

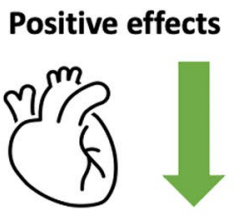

CAD

Atrial Fibrillation (67\%)

Thrombosis

CVD (70\%)
Rheumatic diseases with Covid-19

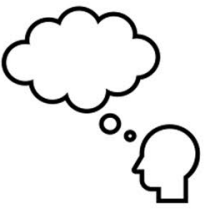

Negative effects

Retinopathy (17\%)

GI upsets (nausea, vomiting) (10\%)

Sensorimotor dysfunction (1.7\%)

Dermatologic effects (3.4\%)

QTC Prolongation (7 - 12\%)

Usage of HCQ in COVID-19 is of questionable safety due to the prolongation of QTc which is associated with a risk of SCD. Administration of HCQ reduced the risk of CVD when used in rheumatic diseases.

The safety and utility of HCQ in the setting of Covid-19 in rheumatic diseases is unknown.

Fig. 1 Summary of effects of hydroxychloroquine in COVID-19 and rheumatic diseases 
is impaired due to interaction of the virus with ACE-2, hence resulting in hypokalemia which predisposes the patient to tachyarrhythmias [63].

Stress-induced cardiomyopathy (Takotsubo syndrome) and Overactivation of Autonomic Nervous System.

Severe SARS-COV2 infection with its associated fears, results in enhancement of physiologic stress in patients which stimulates the sympathetic system [64]. This leads to tachycardia, hypertension and vasoconstriction of coronary vessels, thus predisposing an individual towards arrhythmias and infarction [10], or even (HFpEF) [13]. Furthermore, stress causes increased aggregation of platelets leading to thrombus formation [65]. Apart from this, virus-induced vagal nerve injury, which leads to autonomic imbalances, can further exacerbate the catecholamine release causing negative effects such as stress-induced cardiomyopathy [12, $49,66]$.

\section{Hydroxychloroquine as a potential therapeutic agent}

Hydroxychloroquine (HCQ), an analogue of Chloroquine (CQ), has been used as an antimalarial drug since 1955 [66-68]. It is also employed as an anti-inflammatory drug in the treatment of autoimmune diseases like Systemic Lupus Erythematous (SLE) and Rheumatoid arthritis (RA) [2, 29, 66-69]. Recently, several studies have shown it to be effective for the treatment of COVID-19 [70]. In fact, Yao et al. found HCQ to be more potent and safer than CQ in COVID-19 treatment; thus, it is considered as the drug of choice [71]. Due to similarities between the pathogenesis of rheumatic diseases and COVID-19, the use of HCQ can aid in controlling the virus, according to Najafi et al. [72].

\section{Mechanism of action}

HCQ has been found to mediate anti-viral and anti-inflammatory effects via several mechanisms. It blocks viral entry by raising the $\mathrm{pH}$ of endosomal vesicles which prevents fusion of SARS-COV2 with the host cell, and also by inhibiting Quinine reductase 2 which is required for the synthesis of sialic acid, thus preventing glycosylation of ACE2 receptors (binding site of SARS-COV2) [73-76]. Additionally, HCQ is known to interfere with the action of proteases required for modification of newly translated proteins. Using in silico prediction tools, a docking score of -6.3 for HCQ for the COVID-19 main protease suggests higher ability to bind to and inhibit its function, as compared to the other tested drugs [77]. Moreover, it mediates its anti-inflammatory effects by inhibiting IL- 6 and IFN $\alpha$ via reduction of T-cell activation, thus suppressing the cytokine storm [78, 79]. Apart from this, it blocks cGAS (cyclic GMP-AMP synthase)-mediated synthesis of type I interferon (IFN $\beta$ ) and also weakens NK cell cytotoxic function by controlling the conversion of perforins to its active form [80, 81]. Furthermore, in the disease course of COVID-19, zinc has shown to play a role in adaptive immunity and better disease outcomes [82]. Antimalarials such as chloroquine have shown to augment the efficacy of zinc by behaving as an ionophore, therefore aiding in the suppression of COVID-19 virus replication [83].

\section{Pharmacokinetics}

HCQ is a weak base, a property responsible for its main mechanism of alkalization of acidic vesicles [84]. It is widely preferred due to safety in adults as well as children, pregnant women, and those with normal renal function. However, it has a narrow therapeutic window, requiring caution in those with presumed altered pharmacodynamics. Furthermore, it can be given safely during pregnancy [85, 86]. It has also been shown to be severely toxic in cases of overdose [85]. Furthermore, the optimal dosage and course of therapy for COVID-19 are not yet known. Additional studies, especially randomized control trials, are needed to determine the ideal dosage, ensuring both therapeutic and safety profiles [73].

\section{Adverse effects}

HCQ affects several organ systems adversely, particularly the heart and retina [70]. QTc prolongation, arrhythmias particularly torsades de pointes, cardiomyopathy, cardiac arrest and other cardiotoxicities are the most common cardiovascular manifestations $[67,74,78,85,87]$. The effects on the ocular system are also pronounced, ranging from retinopathy and blurry vision to possible blindness $[67,74,78,86]$. HCQ can also lead to gastrointestinal upsets presenting as nausea, vomiting, abdominal cramps, pancreatitis and hepatitis [67, 86]. At times, neurologic and musculoskeletal manifestations like headache, dizziness, confusion, insomnia, sensorimotor dysfunction, hearing loss and mental disturbances can also be experienced by few patients $[67,85]$. Apart from this, HCQ may interfere with metabolic function leading to hypoglycemia and may also cause idiosyncratic reactions, anaphylaxis and skin infections like Pruritis and StevensJohnson syndrome in severe cases $[67,74,85]$. Furthermore, the hematologic system might be affected in certain patients presenting as neutropenia, Lymphopenia and eosinophilia $[85,86]$.

\section{Usage in COVID-19}

Usage of hydroxychloroquine in SARS-COV2-infected patients was authorized by FDA on 28th March 2020 [2, 88]. However, in March 2020, the FDA (U.S. Food and Drug 
Administration) issued an Emergency Use Authorization (EUA) of HCQ. The suggested dose was $800 \mathrm{mg}$ on day one, followed by $400 \mathrm{mg}$ once daily for a week [79]. But later, due to the adverse cardiovascular events associated with the usage of HCQ in COVID patients, FDA revoked the EUA of HCQ [89]. On the other hand, the CDC (Centers for Disease Control and Prevention) recommends avoidance of high-dosage HCQ to avoid untoward effects [79]. However, the existing BSR guidelines do not consider CVD a contraindication when administering HCQ or other DMARDs [90].

Existing data supporting the use of HCQ as a potential therapy against COVID-19 is limited to in-vitro tests showing its anti-viral and anti-inflammatory properties [71, 88, 91-96]. These are summarized in Table 1. However, the larger emerging concern is the continuation of HCQ in patients with RDs when they contract COVID-19. Due to initial attributions of HCQ toxicity in COVID-19 to the higher doses used, rheumatologists may be tempted to speculate that it is safe to continue the drug at lower doses in these patients when they get the viral illness.

\section{Benefits of HCQ treatment for COVID-19}

Since the onset of the pandemic, several centers around the world have closely examined the utility of HCQ in the management of COVID-19 infection, and as prophylaxis. While this translated into a tendency of rheumatologists to overprescribe HCQ in the early pandemic period, the initial enthusiasm faded when a slew of flawed publications failed to demonstrate valid efficacy (as seen in Table 1) [97, 98].

Due to a lack of large-scale clinical trials and small sample sizes; the safety and efficacy of the drug are still not conclusive [66, 67, 73, 79, 86, 99]. More RCTs are needed for validating the therapeutic benefits of HCQ treatment in COVID-19 [100]. Furthermore, in terms of prophylaxis, a single study showed that individuals administered with prophylactic HCQ had a lower percentage of testing positive for the virus and did not show any mortality [92]. Additionally, a systematic review also showed efficient usage of HCQ as prophylactic therapy for COVID-19 in pre-clinical studies, but the absence of clinical studies limits the study finding [101]. Nonetheless, the prophylactic role may be evaluated further keeping in view the safety profile of the drug [101, 102].

Although initial studies pointed towards positive therapeutic effects of HCQ, more recently conducted studies failed to do so. In fact, a recent clinical trial conducted by Self et al. concluded that HCQ did not improve clinical status at day 14 of COVID-19 patients; thus, its use was not supported [103]. However, several reasons may be associated with this trend, such as different in vitro and in vivo results and conduction of recent studies in critically ill patients and, hence, the administration of HCQ in the later stage of the disease; while, most of its mechanisms of inhibition of viral replication are effective during early disease [104]. Therefore, the data available for HCQ show both promising early therapeutic benefits and existing concerns. In fact, an observational study recently published in Lancet, showing a higher risk to benefit ratio of HCQ usage, was later retracted upon critique. Hence, no convincing results are available yet [73]. More research is needed regarding this field, especially in the context of treating COVID-19 with HCQ in rheumatic disease patients [105].

\section{Risk of adverse cardiac effects with the usage of hydroxychloroquine in COVID-19 patients}

In light of the poor evidence supporting the use of immunosuppressive drugs for treatment in COVID-19, it becomes all the more important to examine the toxicity with HCQ in COVID-19. Several studies have been conducted to investigate cardiotoxicity associated with HCQ usage in both nonCOVID and COVID-infected patients [106-110] as shown in Table 2.

\section{Evidence in support of increased risk}

HCQ is not only known to mildly block the human etherà-go-go related gene (hERG) aka KCNH2 that codes for delayed rectifier potassium channel, but also the inward-rectifier potassium channel [111]. This interferes with ventricular repolarization, resulting in a continuous action potential which causes significant prolongation of QT interval [104, 112]. Thus, HCQ is proarrhythmic, increasing the risk of torsades de pointes and other ventricular arrhythmias [66]. In a systematic review comprising of 1515 patients treated with HCQ, about 10\% experienced QT prolongation [112]. A complete atrioventricular block was also noticed in some cases [113]. It is suggested that these findings are more common when high doses are used for a shorter duration and, hence, are said to be dose dependent [79]. This is evident by an RCT conducted by Borba et al. in Brazil, where patients given a high dose of HCQ experienced arrhythmias within 2-3 days of the administration, while 11 patients died on the 6th day. Over $25 \%$ of the high-dose patients developed a prolonged QTc $>500 \mathrm{~ms}$, with increased mortality in comparison to the other group (17\% vs $13.5 \%)$ [114]. In addition, a report of 3 cases also showed sudden cardiac death in all three patients who initially had normal ECG and were administered $\mathrm{HCQ}$, along with lopinavir/ritonavir and other regimens addressing their existing comorbidities. Hence, it is suggested that the cardiac arrest was due to the proarrhythmic effects of HCQ which along with Lopinavir/Ritonavir could have led to QTc prolongation and development of TdP. However, the ECG of patients prior to death was not available to confirm the hypothesis [46]. Thus, prolonged 


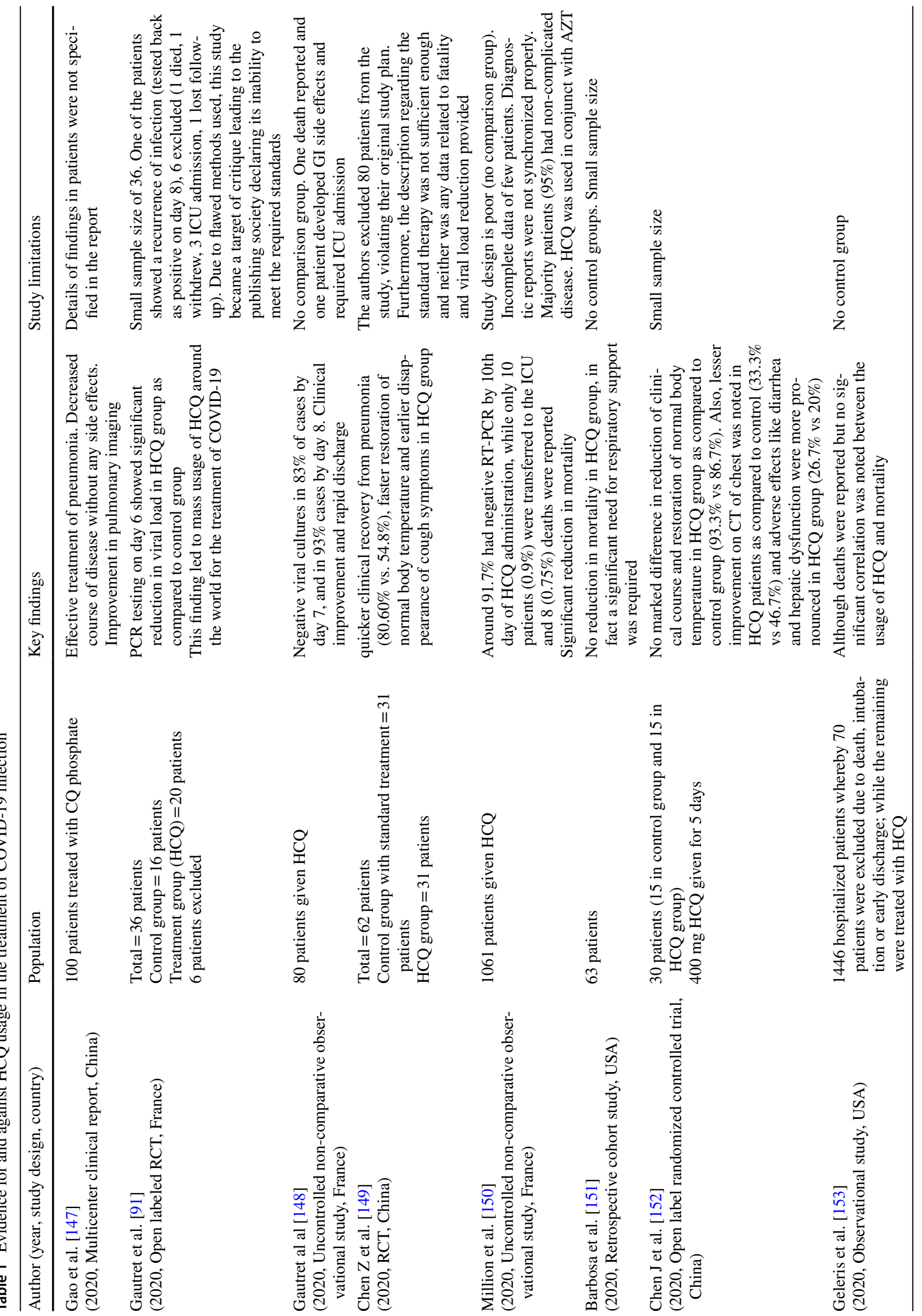




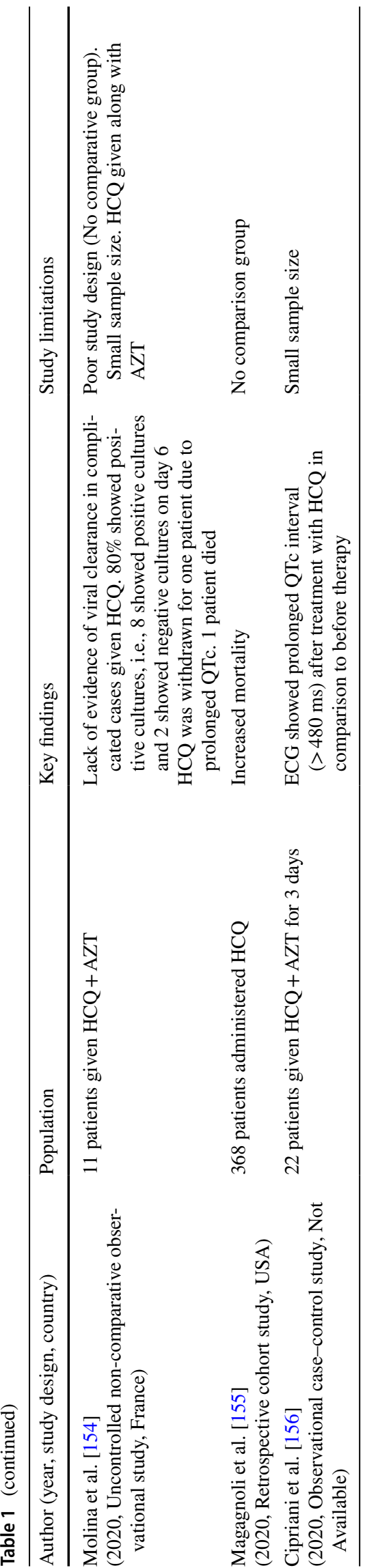

intake of HCQ has shown to result in heart conduction defects, hypotension, cardiomyopathy, cardiac arrest and sudden cardiac death.

\section{Evidence against an increased risk}

Although, apart from the usage of drugs that prolongs QT, several other reasons might be associated with cardiac complications that occur in COVID-19 patients on HCQ therapy. It has been noticed that in general, patients with a pre-existing CVD tend to have longer QT intervals. Additionally, studies have also shown that COVID-19 patients usually have a higher than normal baseline QT levels, even before the start of HCQ therapy $[115,116]$. This could be due to underlying comorbidities, such as diabetes which, along with the medications, may be responsible for longer QT intervals [117, 118]. Furthermore, as mentioned previously, the cytokine storm in SARS-COV-2-infected patients, marked by inflammatory cytokines like IL-1, IL-6, is also known to prolong QT intervals [55]. Impaired RAAS in such patients could also lead to hypokalemia which affects ventricular repolarization [119]. Hence, these factors may be the culprits behind cardiac complications in COVID-19 patients receiving HCQ therapy, rather than the drug itself.

\section{Cardiac safety of Quinolines in non-COVID population}

While the evidence to support an increased risk is limited a handful of case reports from the previous decade, large well-controlled studies have demonstrated a decreased CV risk with the administration of HCQ (Table 3) [120-122].

The risk of QTc prolongation is nearly one-third (7\% versus 25\%) of that described in the setting of COVID-19, with a mere $1.5 \%$ exhibiting a QTc $>500 \mathrm{~ms}$. In fact, in a subset of 591 patients who also had a pretreatment electrocardiogram, mean QTc increased from $424.4 \pm 29.7 \mathrm{~ms}$ to $432.0 \pm 32.3 \mathrm{~ms}(\mathrm{P}<0.0001)$ during HCQ treatment. QTc $>470$ ms during HCQ treatment was associated with greater mortality risk in univariable but not in multivariable analysis [123]. Furthermore, a systematic review in 35,548 patients sealed the argument with no documented risk of adverse cardiac effects [124].

\section{Cardio-protective effect of Quinolines in the non-COVID population}

A systematic review by Liu et al. whereby HCQ was given to 19,679 patients with rheumatic disease showed a $30 \%$ reduction in risk of developing CVD [125]. 


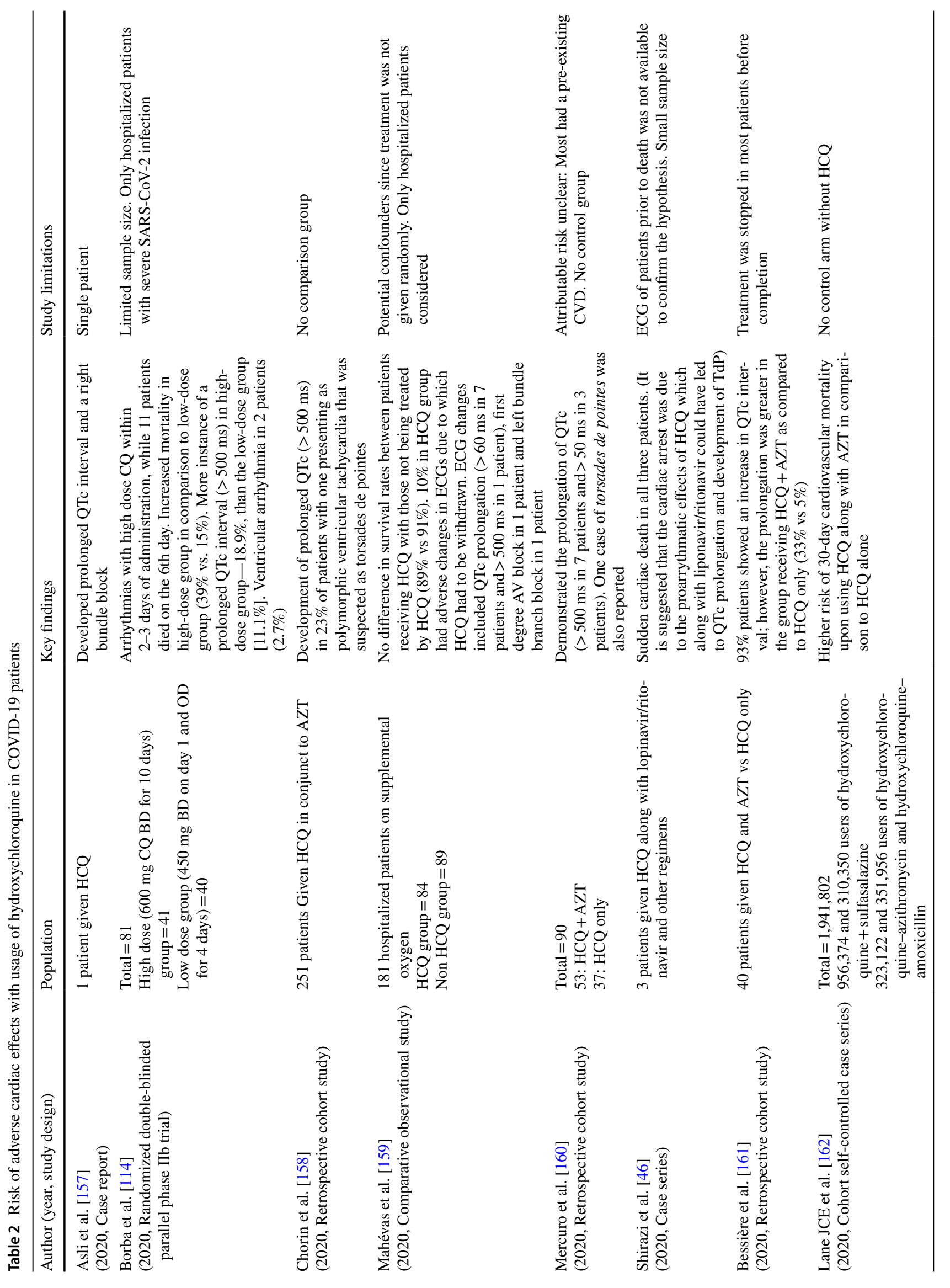




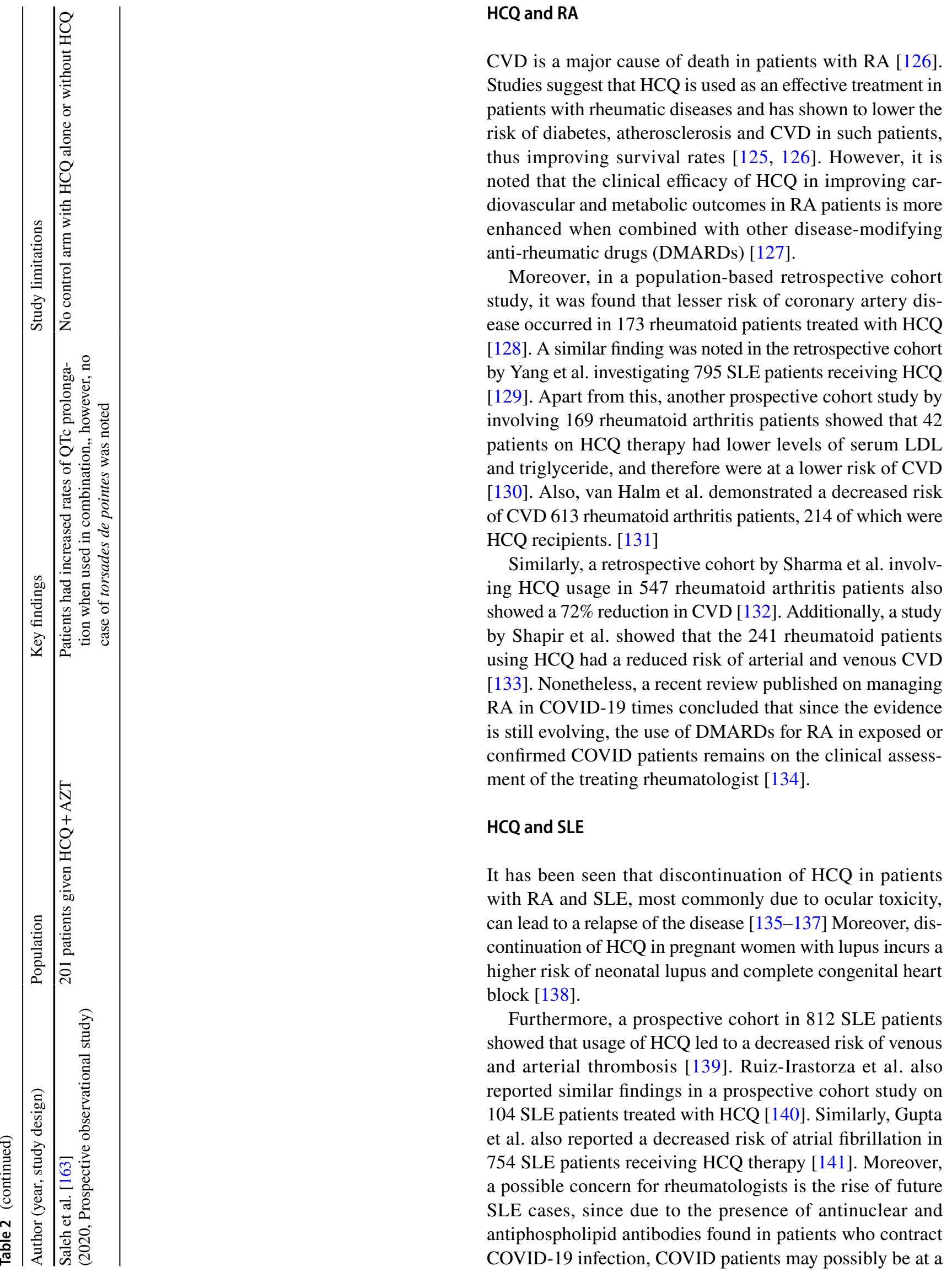


Table 3 Risk of sudden cardiac death with usage of HCQ in non-COVID-19 patients

\begin{tabular}{ll}
\hline Author (year, study design) & Population \\
\hline Chen et al. [120] & $\begin{array}{l}\text { 1 patient given } 200 \text { mg daily HCQ } \\
\text { given for 1 year along with } \\
\text { (2006, Case report) }\end{array}$ \\
$\begin{array}{l}\text { prednisolone }\end{array}$
\end{tabular}

Morgan et al. [121]

(2013, Case report)

O'laughlin et al. [122]

(2016, Case report)

Hooks et al. [122]

(2020, Retrospective cohort study)
1 patient given HCQ

1 patient given $\mathrm{HCQ}$

819 patients with RD given HCQ
Haeusler et al. [124]

(2018, Systematic review)

Hung et al. [128]

(2018, Retrospective cohort)

Liu et al. [125]

(2018, Systematic review)

Konig et al. [139]

(2020, Prospective cohort study)

Ruiz-Irastorza et al. [140]

(2006, Prospective cohort study)

Rho et al. [130]

(2009, Prospective cohort study)

Van Halm et al. [131]

(2006, Retrospective cohort study)

Sharma et al. [132]

(2016, Retrospective cohort study)

Shapiro et al. [133]

(2016, Retrospective cohort study)

Gupta et al. [141]

(2016, Retrospective cohort study)

Yang et al. [129]

(2019, Retrospective cohort study)

Key findings

Study limitations

Prolonged QTc interval. Progress- Single patient

ing to Torsades de Pointes.

After discontinuing HCQ, the

QT interval was shorter, and the patient recovered after treatment with lidocaine and isoproterenol

QTc prolongation

Increased QTc interval

HCQ was associated with QT prolongation in a significant proportion, especially in $\mathrm{CKD}, \mathrm{AF}$ and heart failure. 55 (7\%) had QTc 470-500 ms, 12 (1.5\%) had QTc $>500$ ms. In 591 (subset with pretreatment ECG), QTc increased from $424.4 \pm 29.7 \mathrm{~ms}$ to $432.0 \pm 32.3 \mathrm{~ms}(\mathrm{P}<.0001)$ while on HCQ treatment. QTc $>470$ ms during HCQ treatment was associated with a higher mortality risk in univariable but not in multivariable analysis

35,548 malaria patients given quinoline and its structural derivatives

173 RA patients given HCQ

19,679 patients with RD given HCQ/CQ

812 SLE patients given HCQ

104 SLE patients given HCQ

169 RA patients, of which 42 used HCQ

613 patients, 214 of which were HCQ recipients

547 RA patients given HCQ

541 RA patients, from which HCQ was given to 241.273 were nontreated

1646 SLE Patients, from which HCQ usage by 754 patients 795 SLE patients given HCQ

Did not present any finding of cardiac complications

Lower CAD risk

$30 \%$ CVD risk reduction

Decreased risk of thrombosis, and hence lesser damage to heart

Reduced thrombosis

Those using HCQ had lower levels of serum LDL and triglyceride, and therefore a lower risk of CVD

Decreased risk of CVD

72\% CVD risk reduction

Reduced risk of arterial and venous CVD

$67 \%$ decreased risk of atrial fibrillation

Lower risk of coronary artery disease, however no lowering of stroke
Single patient

Single patient

No clear limitations given. No comparison group
No clear limitations given. No comparison group

No clear limitations given. No comparison group

No clear limitations given. No comparison group

No comparison group. Allocation bias

No comparison group. Allocation bias

No clear limitations given. No comparison group

No comparison group. Sampling bias

No clear limitations given. No comparison group

No clear limitations given. No comparison group

No clear limitations given. No comparison group higher risk of developing lupus spectrum disease later on in life [142]. Overactivation of the interferon axis in the immune response against COVID-19, more so in women due to the location of numerous immune response elements on the $\mathrm{X}$ chromosome, may possibly trigger autoimmune diseases such as SLE in genetically predisposed individuals. 


\section{Ongoing clinical trials}

Due to the concerns associated with safe therapeutic usage of HCQ during COVID-19 treatment and lack of RCTs to provide conclusive evidence, several clinical trials have been proposed across the globe to investigate the aforementioned dilemma. A total of 3237 studies are currently registered at US NIH's National Library of Medicine portal (https://www. clinicaltrials.gov/ct2/home) from 114 countries, of which 793 are investigating various treatment options in COVID19. Amongst these, a total of 68 studies refer to HCQ usage in COVID-19, of which 49 are recruiting, not yet recruiting or active but not recruiting, 12 have been suspended/terminated or withdrawn, while 7 are completed. Some of the ongoing trials are listed in Supplementary Table 1 as given in Online Resource 1.

\section{COVID-19 as the forerunner to SCD in COVID-19 in patients not exposed to HCQ}

It is noticed that majority of the sudden deaths are associated with an underlying cardiovascular manifestation, mainly coronary artery disease (CAD) [143]. In a retrospective cohort study in China, comprising of 191 hospitalized adult patients, the majority with a pre-existing CVD, 23\% experienced a heart failure, while $17 \%$ were also noted to have raised troponin levels [144]. Therefore, SCD and sudden cardiac arrest are not uncommon features and is usually related to abnormalities in the conduction system of heart, such as prolonged QT interval, or a structural dysfunction of cardiac system, such as ischemic heart disease, thus leading to arrhythmias [145].

Similarly, SARS-Cov2 is known to cause both direct and indirect injury to cardiac cells, with arrhythmias being the most common associated complication [146]. This is seen to be further aggravated in patients with a pre-existing CVD and those being administered medications like HCQ, which prolong the QT interval resulting in TdP and sudden cardiac death [66].

\section{Conclusion}

Therefore, evidently, the usage of HCQ in treatment of SLE, rheumatoid arthritis, and other rheumatic diseases showed a reduced risk of CVD, as opposed to its usage in COVID-19 patients; whereby, it is observed to result in QTc prolongation and TdP even in patients with no underlying cardiovascular comorbidity. This is occasionally associated with sudden cardiac death or cardiac arrest, more so when used in combination with other drugs. Although we do not have substantial evidence yet of COVID-19 implications in rheumatic diseases treated with HCQ, the benefits of HCQ usage in rheumatic disease treatment still may outweigh the risks, yet this is pending further validation. Nonetheless, although cardiac complications are less frequently reported, HCQ still may potentially cause mortality. Hence, its clinical benefit needs to be further investigated and justified by future largescale RCTs.

Author contributions Conceptualization: LG, VA. Investigation/Data Curation: HAR, JT, LG. Writing - Original Draft: HAR, JT. Visualization: HAR, JT, LG, VA. Diagrams: HAR, LG. Review and Editing for critical intellectual inputs: HAR, LG, VA.

Funding This study was not funded.

Data availability Not applicable.

Code availability Not applicable.

\section{Compliance with ethical standards}

Conflict of interest None declared.

Consent for publications No part of this review, including graphics, tables and text, are copied or published elsewhere in any languages.

\section{References}

1. Dixon DL, Van Tassell BW, Vecchié A et al (2020) Cardiovascular considerations in treating patients with coronavirus disease 2019 (COVID-19). J Cardiovasc Pharmacol 75:359-367. https:// doi.org/10.1097/FJC.0000000000000836

2. Li X, Wang Y, Agostinis P et al (2020) Is hydroxychloroquine beneficial for COVID-19 patients? Cell Death Dis 11:512. https ://doi.org/10.1038/s41419-020-2721-8

3. Misra DP, Gasparyan AY, Zimba O (2020) Benefits and adverse effects of hydroxychloroquine, methotrexate and colchicine: searching for repurposable drug candidates. Rheumatol Int 40:1741-1751. https://doi.org/10.1007/s00296-020-04694-2

4. Venerito V, Lopalco G, Iannone F (2020) COVID-19, rheumatic diseases and immunosuppressive drugs: an appeal for medication adherence. Rheumatol Int 40:827-828. https://doi.org/10.1007/ s00296-020-04566-9

5. Misra DP, Agarwal V, Gasparyan AY, Zimba O (2020) Rheumatologists' perspective on coronavirus disease 19 (COVID-19) and potential therapeutic targets. Clin Rheumatol 39:2055-2062. https://doi.org/10.1007/s10067-020-05073-9

6. Pablos JL, Galindo M, Carmona L et al (2020) Clinical outcomes of hospitalised patients with COVID-19 and chronic inflammatory and autoimmune rheumatic diseases: a multicentric matched cohort study. Ann Rheum Dis 79:1544-1549. https:// doi.org/10.1136/annrheumdis-2020-218296

7. D'Silva KM, Serling-Boyd N, Wallwork R et al (2020) Clinical characteristics and outcomes of patients with coronavirus disease 2019 (COVID-19) and rheumatic disease: a comparative cohort study from a US "hot spot.” Ann Rheum Dis 79:1156-1162. https ://doi.org/10.1136/annrheumdis-2020-217888

8. Cau R, Bassareo P, Saba L (2020) Cardiac involvement in COVID-19-assessment with echocardiography and cardiac 
magnetic resonance imaging. SN Compr Clin Med. https:// doi.org/10.1007/s42399-020-00344-7

9. Parohan M, Yaghoubi S, Seraji A (2020) Cardiac injury is associated with severe outcome and death in patients with Coronavirus disease 2019 (COVID-19) infection: a systematic review and meta-analysis of observational studies. Eur Heart J Acute Cardiovasc Care. https://doi.org/10.1177/2048872620937165

10. Wu L, O'Kane AM, Peng H et al (2020) SARS-CoV-2 and cardiovascular complications: from molecular mechanisms to pharmaceutical management. Biochem Pharmacol 178:114114. https://doi.org/10.1016/j.bcp.2020.114114

11. Kunal S, Gupta K, Sharma SM et al (2020) Cardiovascular system and COVID-19: perspectives from a developing country. Monaldi Arch Chest Dis. https://doi.org/10.4081/monal di.2020.1305

12. Ranard LS, Fried JA, Abdalla M et al (2020) Approach to acute cardiovascular complications in COVID-19 infection. Circ Heart Fail 13:e007220. https://doi.org/10.1161/CIRCH EARTFAILURE.120.007220

13. Freaney PM, Shah SJ, Khan SS (2020) COVID-19 and heart failure with preserved ejection fraction. JAMA. https://doi. org/10.1001/jama.2020.17445

14. Huang C, Wang Y, Li X et al (2020) Clinical features of patients infected with 2019 novel coronavirus in Wuhan, China. Lancet 395:497-506. https://doi.org/10.1016/S0140 $-6736(20) 30183-5$

15. Liu PP, Blet A, Smyth D, Li H (2020) The science underlying COVID-19: implications for the cardiovascular system. Circulation 142:68-78. https://doi.org/10.1161/CIRCULATIO NAHA. 120.047549

16. Alsaied T, Aboulhosn JA, Cotts TB et al (2020) Coronavirus disease 2019 (COVID-19) Pandemic Implications in pediatric and adult congenital heart disease. J Am Heart Assoc 9:e017224. https://doi.org/10.1161/JAHA.120.017224

17. Zheng Y-Y, Ma Y-T, Zhang J-Y, Xie X (2020) COVID-19 and the cardiovascular system. Nat Rev Cardiol 17:259-260. https://doi. org/10.1038/s41569-020-0360-5

18. Gasparyan AY, Ayvazyan L, Blackmore H, Kitas GD (2011) Writing a narrative biomedical review: considerations for authors, peer reviewers, and editors. Rheumatol Int 31:14091417. https://doi.org/10.1007/s00296-011-1999-3

19. Mortality, Risk Factors of Patients With Cardiac Injury and COVID-19. https://www.ajmc.com/view/mortality-risk-factorsof-patients-with-cardiac-injury-and-covid19. Accessed $16 \mathrm{Nov}$ 2020

20. Kwong JC, Schwartz KL, Campitelli MA et al (2018) Acute myocardial infarction after laboratory-confirmed influenza infection. N Engl J Med 378:345-353. https://doi.org/10.1056/NEJMo a1702090

21. Smeeth L, Thomas SL, Hall AJ et al (2004) Risk of myocardial infarction and stroke after acute infection or vaccination. $\mathrm{N}$ Engl J Med 351:2611-2618. https://doi.org/10.1056/NEJMoa041747

22. Bonow RO, Fonarow GC, O'Gara PT, Yancy CW (2020) Association of coronavirus disease 2019 (COVID-19) with myocardial injury and mortality. JAMA Cardiol 5:751-753

23. Shi S, Qin M, Shen B et al (2020) Association of cardiac injury with mortality in hospitalized patients with COVID-19 in Wuhan, China. JAMA Cardiol 5:802-810. https://doi.org/10.1001/jamac ardio. 2020.0950

24. Wu C, Hu X, Song J et al (2020) Heart injury signs are associated with higher and earlier mortality in coronavirus disease 2019 (COVID-19). medRxiv. https://doi.org/https://doi. org/10.1101/2020.02.26.20028589. Accessed 16 November 2020

25. Dhakal BP, Sweitzer NK, Indik JH et al (2020) SARS-CoV-2 infection and cardiovascular disease: COVID-19 heart. Heart Lung Circ 29:973-987. https://doi.org/10.1016/j.hlc.2020.05.101
26. Kohli U, Lodha R (2020) Cardiac involvement in children with COVID-19. Indian Pediatr 57:936-939

27. Chan JF-W, Yuan S, Kok K-H et al (2020) A familial cluster of pneumonia associated with the 2019 novel coronavirus indicating person-to-person transmission: a study of a family cluster. Lancet 395:514-523. https://doi.org/10.1016/S0140-6736(20)30154-9

28. Li B, Yang J, Zhao F et al (2020) Prevalence and impact of cardiovascular metabolic diseases on COVID-19 in China. Clin Res Cardiol 109:531-538. https://doi.org/10.1007/s00392-020-01626 $-9$

29. Groß S, Jahn C, Cushman S et al (2020) SARS-CoV-2 receptor ACE2-dependent implications on the cardiovascular system: From basic science to clinical implications. J Mol Cell Cardiol 144:47-53. https://doi.org/10.1016/j.yjmcc.2020.04.031

30. Nishiga M, Wang DW, Han Y et al (2020) COVID-19 and cardiovascular disease: from basic mechanisms to clinical perspectives. Nat Rev Cardiol 17:543-558. https://doi.org/10.1038/ s41569-020-0413-9

31. Liu X, Long C, Xiong Q et al (2020) Association of angiotensin converting enzyme inhibitors and angiotensin II receptor blockers with risk of COVID-19, inflammation level, severity, and death in patients with COVID-19: a rapid systematic review and meta-analysis. Clin Cardiol. https://doi.org/10.1002/clc.23421

32. Bozkurt B, Kovacs R, Harrington B (2020) Joint HFSA/ACC/ AHA statement addresses concerns Re: using RAAS antagonists in COVID-19. J Card Fail 26:370. https://doi.org/10.1016/j.cardf ail.2020.04.013

33. Gao C, Cai Y, Zhang K et al (2020) Association of hypertension and antihypertensive treatment with COVID-19 mortality: a retrospective observational study. Eur Heart J 41:2058-2066. https://doi.org/10.1093/eurheartj/ehaa433

34. Talasaz AH, Kakavand H, Van Tassell B et al (2020) Cardiovascular complications of COVID-19: pharmacotherapy perspective. Cardiovasc Drugs Ther. https://doi.org/10.1007/s1055 7-020-07037-2

35. Xiong T-Y, Redwood S, Prendergast B, Chen M (2020) Coronaviruses and the cardiovascular system: acute and long-term implications. Eur Heart J 41:1798-1800. https://doi.org/10.1093/ eurheartj/ehaa231

36. Topol EJ (2020) COVID-19 can affect the heart. Science 370:408-409. https://doi.org/10.1126/science.abe2813

37. Zhang H, Penninger JM, Li Y et al (2020) Angiotensin-converting enzyme 2 (ACE2) as a SARS-CoV-2 receptor: molecular mechanisms and potential therapeutic target. Intensive Care Med 46:586-590. https://doi.org/10.1007/s00134-020-05985-9

38. Aghagoli G, Gallo Marin B, Soliman LB, Sellke FW (2020) Cardiac involvement in COVID-19 patients: risk factors, predictors, and complications: a review. J Card Surg 35:1302-1305. https:// doi.org/10.1111/jocs. 14538

39. Guzik TJ, Mohiddin SA, Dimarco A et al (2020) COVID-19 and the cardiovascular system: implications for risk assessment, diagnosis, and treatment options. Cardiovasc Res 116:1666-1687. https://doi.org/10.1093/cvr/cvaa106

40. Babapoor-Farrokhran S, Gill D, Walker J et al (2020) Myocardial injury and COVID-19: possible mechanisms. Life Sci 253:117723. https://doi.org/10.1016/j.lfs.2020.117723

41. Libby P (2020) The Heart in COVID-19: primary target or secondary bystander? JACC Basic Transl Sci 5:537-542. https://doi. org/10.1016/j.jacbts.2020.04.001

42. Mitrani RD, Dabas N, Goldberger JJ (2020) COVID-19 cardiac injury: Implications for long-term surveillance and outcomes in survivors. Heart Rhythm 17:1984-1990. https://doi. org/10.1016/j.hrthm.2020.06.026

43. Ferrario CM, Chappell MC, Tallant EA et al (1997) Counterregulatory actions of angiotensin-(1-7). Hypertension 30:535-541. https://doi.org/10.1161/01.hyp.30.3.535 
44. Kang Y, Chen T, Mui D et al (2020) Cardiovascular manifestations and treatment considerations in COVID-19. Heart 106:1132-1141. https://doi.org/10.1136/heartjnl-2020-317056

45. Yao XH, Li TY, He ZC et al (2020) A pathological report of three COVID-19 cases by minimal invasive autopsies. Zhonghua Bing Li Xue Za Zhi 49:411-417. https://doi.org/10.3760/cma.j.cn112 151-20200312-00193

46. Shirazi S, Mami S, Mohtadi N et al (2020) Sudden cardiac death in COVID-19 patients, a report of three cases. Future Cardiol. https://doi.org/10.2217/fca-2020-0082

47. Inciardi RM, Lupi L, Zaccone G et al (2020) Cardiac involvement in a patient with coronavirus disease 2019 (COVID-19). JAMA Cardiol 5:819-824. https://doi.org/10.1001/jamacardio .2020 .1096

48. Fox SE, Akmatbekov A, Harbert JL et al (2020) Pulmonary and cardiac pathology in African American patients with COVID19: an autopsy series from New Orleans. Lancet Respir Med 8:681-686. https://doi.org/10.1016/S2213-2600(20)30243-5

49. Hendren NS, Drazner MH, Bozkurt B, Cooper LT Jr (2020) Description and proposed management of the acute COVID-19 cardiovascular syndrome. Circulation 141:1903-1914. https:// doi.org/10.1161/CIRCULATIONAHA.120.047349

50. Soy M, Keser G, Atagündüz $P$ et al (2020) Cytokine storm in COVID-19: pathogenesis and overview of anti-inflammatory agents used in treatment. Clin Rheumatol 39:2085-2094. https ://doi.org/10.1007/s10067-020-05190-5

51. Xu H, Hou K, Xu R et al (2020) Clinical characteristics and risk factors of cardiac involvement in COVID-19. J Am Heart Assoc 9:e016807. https://doi.org/10.1161/JAHA.120.016807

52. Sanna G, Serrau G, Bassareo PP et al (2020) Children's heart and COVID-19: Up-to-date evidence in the form of a systematic review. Eur J Pediatr 179:1079-1087. https://doi.org/10.1007/ s00431-020-03699-0

53. Dunga SK, Sundaram TG, Kavadichanda CG (2020) Pathogenesis of muscle weakness in inflammatory myositis. Indian Journal of Rheumatology. https://www.indianjrheumatol.com/preprintar ticle. $a s p ? i d=291069$. Accessed 16 Nov 2020

54. Guo T, Fan Y, Chen M et al (2020) Cardiovascular implications of fatal outcomes of patients with coronavirus disease 2019 (COVID-19). JAMA Cardiol 5:811-818. https://doi.org/10.1001/ jamacardio.2020.1017

55. Lazzerini PE, Boutjdir M, Capecchi PL (2020) COVID19, arrhythmic risk, and inflammation: mind the gap! Circulation 142:7-9. https://doi.org/10.1161/CIRCULATIO NAHA. 120.047293

56. Driggin E, Madhavan MV, Bikdeli B et al (2020) Cardiovascular considerations for patients, health care workers, and health systems during the COVID-19 pandemic. J Am Coll Cardiol 75:2352-2371. https://doi.org/10.1016/j.jacc.2020.03.031

57. Wang D, Hu B, Hu C et al (2020) Clinical characteristics of 138 hospitalized patients with 2019 novel coronavirus-infected pneumonia in Wuhan, China. JAMA 323:1061-1069. https://doi. org/10.1001/jama.2020.1585

58. Kwenandar F, Japar KV, Damay V et al (2020) Coronavirus disease 2019 and cardiovascular system: a narrative review. Int J Cardiol Heart Vasc 29:100557. https://doi.org/10.1016/j.ijcha .2020 .100557

59. Bansal M (2020) Cardiovascular disease and COVID-19. Diabetes Metab Syndr 14:247-250. https://doi.org/10.1016/j. dsx.2020.03.013

60. Varga Z, Flammer AJ, Steiger P et al (2020) Endothelial cell infection and endotheliitis in COVID-19. Lancet 395:1417-1418. https://doi.org/10.1016/S0140-6736(20)30937-5

61. Ahmed S, Zimba O, Gasparyan AY (2020) Thrombosis in Coronavirus disease 2019 (COVID-19) through the prism of
Virchow's triad. Clin Rheumatol 39:2529-2543. https://doi. org/10.1007/s10067-020-05275-1

62. O'Sullivan JM, Gonagle DM, Ward SE et al (2020) Endothelial cells orchestrate COVID-19 coagulopathy. Lancet Haematol 7:e553-e555

63. Chen D, Li X, Song Q et al (2020) Hypokalemia and Clinical Implications in Patients with Coronavirus Disease 2019 (COVID-19). medRxiv. https://doi.org/https://doi. org/10.1101/2020.02.27.20028530. Accessed 15 November 2020

64. Rozanski A, Blumenthal JA, Kaplan J (1999) Impact of psychological factors on the pathogenesis of cardiovascular disease and implications for therapy. Circulation 99:2192-2217. https://doi. org/10.1161/01.cir.99.16.2192

65. Yaribeygi H, Panahi Y, Sahraei H et al (2017) The impact of stress on body function: a review. EXCLI J 16:1057-1072. https ://doi.org/10.17179/excli2017-480

66. Manolis AS, Manolis AA, Manolis TA et al (2020) COVID-19 infection and cardiac arrhythmias. Trends Cardiovasc Med. https ://doi.org/10.1016/j.tcm.2020.08.002

67. Abena PM, Decloedt EH, Bottieau E et al (2020) Chloroquine and hydroxychloroquine for the prevention or treatment of COVID-19 in Africa: caution for inappropriate off-label use in healthcare settings. Am J Trop Med Hyg 102:1184-1188. https ://doi.org/10.4269/ajtmh.20-0290

68. Ingraham NE, Boulware D, Sparks MA et al (2020) Shining a light on the evidence for hydroxychloroquine in SARS-CoV-2. Crit Care 24:182. https://doi.org/10.1186/s13054-020-02894-7

69. Pereira BB (2020) Challenges and cares to promote rational use of chloroquine and hydroxychloroquine in the management of coronavirus disease 2019 (COVID-19) pandemic: a timely review. J Toxicol Environ Health B Crit Rev 23:177-181. https ://doi.org/10.1080/10937404.2020.1752340

70. Cairoli E, Espinosa G (2020) Hydroxychloroquine in the treatment of COVID-19: how to use it waiting for conclusive scientific evidence. Med Clin 155:134-135. https://doi.org/10.1016/j. medcle.2020.05.003

71. Yao X, Ye F, Zhang M et al (2020) In vitro antiviral activity and projection of optimized dosing design of hydroxychloroquine for the treatment of severe acute respiratory syndrome coronavirus 2 (SARS-CoV-2). Clin Infect Dis 71:732-739

72. Najafi S, Rajaei E, Moallemian R, Nokhostin F (2020) The potential similarities of COVID-19 and autoimmune disease pathogenesis and therapeutic options: new insights approach. Clin Rheumatol 39:3223-3235. https://doi.org/10.1007/s1006 7-020-05376-X

73. Nittari G, Pallotta G, Amenta F, Tayebati SK (2020) Current pharmacological treatments for SARS-COV-2: a narrative review. Eur J Pharmacol 882:173328. https://doi.org/10.1016/j. ejphar.2020.173328

74. Meyerowitz EA, Vannier AGL, Friesen MGN et al (2020) Rethinking the role of hydroxychloroquine in the treatment of COVID-19. FASEB J 34:6027-6037. https://doi.org/10.1096/ fj.202000919

75. Ibáñez S, Martínez O, Valenzuela F et al (2020) Hydroxychloroquine and chloroquine in COVID-19: should they be used as standard therapy? Clin Rheumatol 39:2461-2465. https://doi. org/10.1007/s10067-020-05202-4

76. Hashem AM, Alghamdi BS, Algaissi AA et al (2020) Therapeutic use of chloroquine and hydroxychloroquine in COVID-19 and other viral infections: a narrative review. Travel Med Infect Dis 35:101735. https://doi.org/10.1016/j.tmaid.2020.101735

77. Baildya N, Ghosh NN, Chattopadhyay AP (2020) Inhibitory activity of hydroxychloroquine on COVID-19 main protease: an insight from MD-simulation studies. J Mol Struct 1219:128595. https://doi.org/10.1016/j.molstruc.2020.128595 
78. Palmeira VA, Costa LB, Perez LG et al (2020) Do we have enough evidence to use chloroquine/hydroxychloroquine as a public health panacea for COVID-19? Clinics 75:e1928. https ://doi.org/10.6061/clinics/2020/e1928

79. Alanagreh 'ai L, Alzoughool F, Atoum M (2020) Risk of using hydroxychloroquine as a treatment of COVID-19. Int J Risk Saf Med 31:111-116. https://doi.org/10.3233/JRS-200024

80. An J, Woodward JJ, Sasaki T et al (2015) Cutting edge: antimalarial drugs inhibit IFN- $\beta$ production through blockade of cyclic GMP-AMP synthase-DNA interaction. J Immunol 194:40894093. https://doi.org/10.4049/jimmunol.1402793

81. Taylor MA, Bennett M, Kumar V, Schatzle JD (2000) Functional defects of $\mathrm{NK}$ cells treated with chloroquine mimic the lytic defects observed in perforin-deficient mice. J Immunol 165:5048-5053. https://doi.org/10.4049/jimmunol.165.9.5048

82. Rahman MT, Idid SZ (2020) Can Zn Be a critical element in COVID-19 treatment? Biol Trace Elem Res. https://doi. org/10.1007/s12011-020-02194-9

83. Xue J, Moyer A, Peng B et al (2014) Chloroquine is a zinc ionophore. PLoS ONE 9:e109180. https://doi.org/10.1371/journ al.pone. 0109180

84. Zhou D, Dai S-M, Tong Q (2020) COVID-19: a recommendation to examine the effect of hydroxychloroquine in preventing infection and progression. J Antimicrob Chemother 75:1667-1670. https://doi.org/10.1093/jac/dkaa114

85. Juurlink DN (2020) Safety considerations with chloroquine, hydroxychloroquine and azithromycin in the management of SARS-CoV-2 infection. CMAJ 192:E450-E453. https://doi. org/10.1503/cmaj.200528

86. Acharya Y, Sayed A (2020) Chloroquine and hydroxychloroquine as a repurposed agent against COVID-19: a narrative review. Ther Adv Infect Dis 7:2049936120947517. https://doi. org/10.1177/2049936120947517

87. Paumgartten FJR, Delgado IF, da Pitta LR, de Oliveira ACAX (2020) Chloroquine and hydroxychloroquine repositioning in times of COVID-19 pandemics, all that glitters is not gold. Cad Saude Publica 36:e0088520. https://doi.org/10.1590/0102$311 \times 00088520$

88. Nina PB, Dash AP (2020) Hydroxychloroquine as prophylaxis or treatment for COVID-19: What does the evidence say? Indian J Public Health 64:S125-S127. https://doi.org/10.4103/ijph. IJPH_496_20

89. Hydroxychloroquine: Drug information. UpToDate. https://www. uptodate.com/contents/hydroxychloroquine-drug-information. Accessed 15 November 2020

90. Ledingham J, Gullick N, Irving K et al (2017) BSR and BHPR guideline for the prescription and monitoring of non-biologic disease-modifying anti-rheumatic drugs. Rheumatology 56:2257. https://doi.org/10.1093/rheumatology/kex389

91. Gautret P, Lagier J-C, Parola P et al (2020) Hydroxychloroquine and azithromycin as a treatment of COVID-19: results of an open-label non-randomized clinical trial. Int J Antimicrob Agents 56:105949. https://doi.org/10.1016/j.ijantimicag.2020.105949

92. Sen S, Werner A, Shekhar A (2020) Within a large healthcare system, the incidence of positive COVID-19 results and mortality are lower in patients on chronic hydroxychloroquine therapy. Drugs Ther Perspect. https://doi.org/10.1007/s40267-020-00741 $-\mathrm{X}$

93. Arshad S, Kilgore P, Chaudhry ZS et al (2020) Treatment with hydroxychloroquine, azithromycin, and combination in patients hospitalized with COVID-19. Int J Infect Dis 97:396-403. https ://doi.org/10.1016/j.ijid.2020.06.099

94. Chowdhury MDS, Rathod J, Gernsheimer J (2020) A rapid systematic review of clinical trials utilizing chloroquine and hydroxychloroquine as a treatment for COVID-19. Acad Emerg Med 27:493-504. https://doi.org/10.1111/acem.14005
95. Ferner RE, Aronson JK (2020) Chloroquine and hydroxychloroquine in covid-19. BMJ 369:m1432. https://doi.org/10.1136/ bmj.m1432

96. Cohen MS (2020) Hydroxychloroquine for the prevention of covid-19 — searching for evidence. N Engl J Med 383:585-586

97. Gupta L, Misra DP, Agarwal V et al (2020) Management of rheumatic diseases in the time of covid-19 pandemic: perspectives of rheumatology practitioners from India. Ann Rheum Dis. https:// doi.org/10.1136/annrheumdis-2020-217509

98. Misra DP, Agarwal V (2020) Blaming the peer reviewer: Don't shoot the messenger!! Indian Journal of Rheumatology 15:162. https://doi.org/10.4103/injr.injr_187_20

99. Meo SA, Klonoff DC, Akram J (2020) Efficacy of chloroquine and hydroxychloroquine in the treatment of COVID-19. Eur Rev Med Pharmacol Sci 24:4539-4547

100. Gao J, Hu S (2020) Update on use of chloroquine/hydroxychloroquine to treat coronavirus disease 2019 (COVID-19). Biosci Trends 14:156-158. https://doi.org/10.5582/bst.2020.03072

101. Shah S, Das S, Jain A et al (2020) A systematic review of the prophylactic role of chloroquine and hydroxychloroquine in coronavirus disease-19 (COVID-19). Int J Rheum Dis 23:613-619. https://doi.org/10.1111/1756-185X.13842

102. Gurjar M, Agarwal V (2020) Usefulness of hydroxychloroquine for COVID-19: Does answer lie in timing to start? Indian J Rheumatol 15:249

103. Self WH, Semler MW, Leither LM et al (2020) Effect of hydroxychloroquine on clinical status at 14 days in hospitalized patients with covid-19: a randomized clinical trial. JAMA. https://doi. org/10.1001/jama.2020.22240

104. Offerhaus JA, Wilde AAM, Remme CA (2020) Prophylactic (hydroxy)chloroquine in COVID-19: potential relevance for cardiac arrhythmia risk. Heart Rhythm 17:1480-1486

105. Kastritis E, Kitas GD, Vassilopoulos D et al (2020) Systemic autoimmune diseases, anti-rheumatic therapies, COVID-19 infection risk and patient outcomes. Rheumatol Int 40:13531360. https://doi.org/10.1007/s00296-020-04629-x

106. Prodromos CC, Rumschlag T, Perchyk T (2020) Hydroxychloroquine is protective to the heart, not harmful: a systematic review. New Micro New Infect 37:100747. https://doi.org/10.1016/j. nmni.2020.100747

107. Kamp TJ, Hamdan MH, January CT (2020) Chloroquine or hydroxychloroquine for COVID-19: is cardiotoxicity a concern? J Am Heart Assoc 9:e016887. https://doi.org/10.1161/ JAHA.120.016887

108. Mégarbane B, Scherrmann J-M (2020) Hydroxychloroquine and azithromycin to treat patients with COVID-19: both friends and foes? J Clin Pharmacol 60:808-814. https://doi.org/10.1002/ jcph.1646

109. Kalra RS, Tomar D, Meena AS, Kandimalla R (2020) SARSCoV-2, ACE2, and hydroxychloroquine: cardiovascular complications, therapeutics, and clinical readouts in the current settings. Pathogens. https://doi.org/10.3390/pathogens9070546

110. Stevenson A, Kirresh A, Conway S et al (2020) Hydroxychloroquine use in COVID-19: is the risk of cardiovascular toxicity justified? Open Heart 7:e001362

111. Polak S, Wiśniowska B, Brandys J (2009) Collation, assessment and analysis of literaturein vitrodata on hERG receptor blocking potency for subsequent modeling of drugs' cardiotoxic properties. J Appl Toxicol 29:183-206

112. Jankelson L, Karam G, Becker ML et al (2020) QT prolongation, torsades de pointes, and sudden death with short courses of chloroquine or hydroxychloroquine as used in COVID-19: a systematic review. Heart Rhythm 17:1472-1479. https://doi. org/10.1016/j.hrthm.2020.05.008

113. Singh AP, Tousif S, Umbarkar P, Lal H (2020) A pharmacovigilance study of hydroxychloroquine cardiac safety profile: 
potential implication in COVID-19 mitigation. J Clin Med 9:1867

114. Borba MGS, Val FFA, Sampaio VS et al (2020) Effect of high vs low doses of chloroquine diphosphate as adjunctive therapy for patients hospitalized with severe acute respiratory syndrome coronavirus 2 (SARS-CoV-2) infection: a randomized clinical trial. JAMA Netw Open 3:e208857. https:// doi.org/10.1001/jamanetworkopen.2020.8857

115. Anupama BK, Adhikari S, Chaudhuri D (2020) Prolonged qt interval in a patient with coronavirus disease-2019: beyond hydroxychloroquine and azithromycin. J Investig Med High Impact Case Rep 8:2324709620948407. https://doi. org/10.1177/2324709620948407

116. Sinkeler FS, Berger FA, Muntinga HJ, Jansen MMPM (2020) The risk of QTc-interval prolongation in COVID-19 patients treated with chloroquine. Neth Heart J 28:418-423. https://doi. org/10.1007/s12471-020-01462-6

117. Park B, Lee Y-J (2018) Metabolic syndrome and its components as risk factors for prolonged corrected QT interval in apparently healthy Korean men and women. J Clin Lipidol 12:1298-1304. https://doi.org/10.1016/j.jacl.2018.07.004

118. Darpö B (2001) Spectrum of drugs prolonging QT interval and the incidence of torsades de pointes. Eur Heart J Suppl 3:K70-K80. https://doi.org/10.1016/S1520-765X(01)90009-4

119. Belardinelli L, Giles WR, Rajamani S et al (2015) Cardiac late Na current: Proarrhythmic effects, roles in long QT syndromes, and pathological relationship to CaMKII and oxidative stress. Heart Rhythm 12:440-448

120. Chen C-Y, Wang F-L, Lin C-C (2006) Chronic hydroxychloroquine use associated with QT prolongation and refractory ventricular arrhythmia. Clin Toxicol 44:173-175. https://doi. org/10.1080/15563650500514558

121. Morgan ND, Patel SV, Dvorkina O (2013) Suspected hydroxychloroquine-associated QT-interval prolongation in a patient with systemic lupus erythematosus. J Clin Rheumatol 19:286-288

122. O'Laughlin JP, Mehta PH, Wong BC (2016) Life threatening severe QTc prolongation in patient with systemic lupus erythematosus due to hydroxychloroquine. Case Rep Cardiol 2016:1-4

123. Hooks M, Bart B, Vardeny O et al (2020) Effects of hydroxychloroquine treatment on QT interval. Heart Rhythm 17:1930-1935

124. Haeusler IL, Chan XHS, Guérin PJ, White NJ (2018) The arrhythmogenic cardiotoxicity of the quinoline and structurally related antimalarial drugs: a systematic review. BMC Med 16:200. https://doi.org/10.1186/s12916-018-1188-2

125. Liu D, Li X, Zhang Y et al (2018) Chloroquine and hydroxychloroquine are associated with reduced cardiovascular risk: a systematic review and meta-analysis. Drug Des Devel Ther 12:1685-1695. https://doi.org/10.2147/DDDT.S166893

126. Rempenault C, Combe B, Barnetche T et al (2018) Metabolic and cardiovascular benefits of hydroxychloroquine in patients with rheumatoid arthritis: a systematic review and meta-analysis. Ann Rheum Dis 77:98-103. https://doi.org/10.1136/annrheumdi s-2017-211836

127. Rempenault $\mathrm{C}$, Combe B, Barnetche $\mathrm{T}$ et al (2020) Clinical and structural efficacy of hydroxychloroquine in rheumatoid arthritis: a systematic review. Arthritis Care Res 72:36-40. https://doi. org/10.1002/acr.23826

128. Hung Y-M, Wang Y-H, Lin L et al (2018) Hydroxychloroquine may be associated with reduced risk of coronary artery diseases in patients with rheumatoid arthritis: a nationwide populationbased cohort study. Int J Clin Pract 72:e13095

129. Yang D-H, Leong P-Y, Sia S-K et al (2019) Long-term hydroxychloroquine therapy and risk of coronary artery disease in patients with systemic lupus erythematosus. J Clin Med Res. https://doi.org/10.3390/jcm8060796
130. Rho YH, Oeser A, Chung CP et al (2009) Drugs used in the treatment of rheumatoid arthritis: relationship between current use and cardiovascular risk factors. Arch Drug Inf 2:34-40. https ://doi.org/10.1111/j.1753-5174.2009.00019.x

131. van Halm VP, Nurmohamed MT, Twisk JWR et al (2006) Disease-modifying antirheumatic drugs are associated with a reduced risk for cardiovascular disease in patients with rheumatoid arthritis: a case control study. Arthritis Res Ther 8:R151. https://doi.org/10.1186/ar2045

132. Sharma TS, Wasko MCM, Tang X et al (2016) Hydroxychloroquine use is associated with decreased incident cardiovascular events in rheumatoid arthritis patients. J Am Heart Assoc. https ://doi.org/10.1161/JAHA.115.002867

133. Shapiro M, Levy Y (2018) The association between hydroxychloroquine treatment and cardiovascular morbidity among rheumatoid arthritis patients. Oncotarget 9:6615-6622. https://doi. org/10.18632/oncotarget.23570

134. Roongta R, Ghosh A (2020) Managing rheumatoid arthritis during COVID-19. Clin Rheumatol 39:3237-3244. https://doi. org/10.1007/s10067-020-05358-z

135. Fernandez-Ruiz R, Bornkamp N, Kim MY et al (2020) Discontinuation of hydroxychloroquine in older patients with systemic lupus erythematosus: a multicenter retrospective study. Arthritis Res Ther 22:191. https://doi.org/10.1186/s13075-020-02282-0

136. Huang Y, Chen Z, Wang Y et al (2020) Clinical characteristics of 17 patients with COVID-19 and systemic autoimmune diseases: a retrospective study. Ann Rheum Dis 79:1163-1169

137. Aouhab Z, Hong H, Felicelli C et al (2019) Outcomes of systemic lupus erythematosus in patients who discontinue hydroxychloroquine. ACR Open Rheumatol 1:593-599. https://doi. org/10.1002/acr2.11084

138. Finkelstein Y, Adler Y, Harel L et al (1997) Anti-Ro (SSA) and anti-La (SSB) antibodies and complete congenital heart block. Ann Med Interne 148:205-208

139. Konig MF, Li J, Petri M (2020) O1 Hydroxychloroquine blood levels and risk of thrombotic events in systemic lupus erythematous. Lupus Sci Med. https://doi.org/10.1136/lupus-2020-eurol upus. 15

140. Ruiz-Irastorza G, Egurbide MV, Pijoan JI et al (2006) Effect of antimalarials on thrombosis and survival in patients with systemic lupus erythematosus. Lupus 15:577-583. https://doi. org/10.1177/0961203306071872

141. Gupta A (2018) Association of hydroxychloroquine use and incident atrial fibrillation in systemic lupus erythematosus: a retrospective study. 2018 ACR/ARHP Annual Meeting. https:// acr.confex.com/acr/2018/meetingapp.cgi/Paper/75155. Accessed 15 November 2020

142. Kabeerdoss J, Danda D (2020) Understanding immunopathological fallout of human coronavirus infections including COVID-19: will they cross the path of rheumatologists? Int J Rheum Dis. https://doi.org/10.1111/1756-185X.13909

143. Morin DP, Homoud MK, Mark Estes NA (2017) Prediction and prevention of sudden cardiac death. Cardiac Electrophysiol Clin 9:631-638

144. Zhou F, Yu T, Du R et al (2020) Clinical course and risk factors for mortality of adult inpatients with COVID-19 in Wuhan, China: a retrospective cohort study. Lancet 395:1054-1062. https ://doi.org/10.1016/S0140-6736(20)30566-3

145. Kuriachan VP, Sumner GL, Mitchell LB (2015) Sudden cardiac death. Curr Probl Cardiol 40:133-200. https://doi.org/10.1016/j. cpcardiol.2015.01.002

146. Kuck K-H (2020) Arrhythmias and sudden cardiac death in the COVID-19 pandemic. Herz 45:325-326. https://doi.org/10.1007/ s00059-020-04924-0

147. Gao J, Tian Z, Yang X (2020) Breakthrough: Chloroquine phosphate has shown apparent efficacy in treatment of COVID-19 
associated pneumonia in clinical studies. Biosci Trends 14:7273. https://doi.org/10.5582/bst.2020.01047

148. Gautret P, Lagier J-C, Parola P et al (2020) Clinical and microbiological effect of a combination of hydroxychloroquine and azithromycin in 80 COVID-19 patients with at least a six-day follow up: a pilot observational study. Travel Med Infect Dis 34:101663. https://doi.org/10.1016/j.tmaid.2020.101663

149. Chen Z, Hu J, Zhang Z et al (2020) Efficacy of hydroxychloroquine in patients with COVID-19: results of a randomized clinical trial. medRxiv. http://dx.doi.org/https://doi. org/10.1101/2020.03.22.20040758. Accessed 15 November 2020

150. Million M, Lagier J-C, Gautret P et al (2020) Early treatment of COVID-19 patients with hydroxychloroquine and azithromycin: a retrospective analysis of 1061 cases in Marseille. France Travel Med Infect Dis 35:101738. https://doi.org/10.1016/j.tmaid .2020 .101738

151. Barbosa J, Kaitis D, Freedman R et al (2020) Clinical outcomes of hydroxychloroquine in hospitalized patients with COVID-19: a quasi-randomized comparative study. N Engl J Med. https:// aslm.org/wp-content/uploads/2020/06/1589740749-NEJM_Clini cal-Outcomes-of-Hydroxychlorquine-in-Patients-with-COVID 19.pdf?x10839. Accessed 15 November 2020

152. Chen J, Liu D, Liu L et al (2020) A pilot study of hydroxychloroquine in treatment of patients with moderate COVID-19. Zhejiang Da Xue Xue Bao Yi Xue Ban 49:215-219. https://doi. org/10.3785/j.issn.1008-9292.2020.03.03

153. Geleris J, Sun Y, Platt J et al (2020) Observational Study of Hydroxychloroquine in Hospitalized Patients with Covid-19. N Engl J Med 382:2411-2418. https://doi.org/10.1056/NEJMo a2012410

154. Molina JM, Delaugerre C, Le Goff J et al (2020) No evidence of rapid antiviral clearance or clinical benefit with the combination of hydroxychloroquine and azithromycin in patients with severe COVID-19 infection. Med Mal Infect 50:384. https://doi. org/10.1016/j.medmal.2020.03.006

155. Magagnoli J, Narendran S, Pereira F et al (2020) Outcomes of hydroxychloroquine usage in united states veterans hospitalized with COVID-19. Med (N Y). https://doi.org/10.1016/j. medj.2020.06.001

156. Cipriani A, Zorzi A, Ceccato D et al (2020) Arrhythmic profile and 24-hour QT interval variability in COVID-19 patients treated with hydroxychloroquine and azithromycin. Int J Cardiol 316:280-284. https://doi.org/10.1016/j.ijcard.2020.05.036
157. Asli R, Abdullah MS, Chong PL et al (2020) Case report: right bundle brunch block and QTc prolongation in a patient with COVID-19 treated with hydroxychloroquine. Am J Trop Med Hyg 103:79-82

158. Chorin E, Wadhwani L, Magnani S et al (2020) QT interval prolongation and torsade de pointes in patients with COVID-19 treated with hydroxychloroquine/azithromycin. Heart Rhythm 17:1425-1433. https://doi.org/10.1016/j.hrthm.2020.05.014

159. Mahévas M, Tran V-T, Roumier M et al (2020) Clinical efficacy of hydroxychloroquine in patients with covid-19 pneumonia who require oxygen: observational comparative study using routine care data. BMJ 369:m1844. https://doi.org/10.1136/bmj.m1844 .2020May;369

160. Mercuro NJ, Yen CF, Shim DJ et al (2020) Risk of QT Interval prolongation associated with use of hydroxychloroquine with or without concomitant azithromycin among hospitalized patients testing positive for coronavirus disease 2019 (COVID19). JAMA Cardiol 5:1036-1041. https://doi.org/10.1001/jamac ardio.2020.1834

161. Bessière F, Roccia H, Delinière A et al (2020) Assessment of QT intervals in a case series of patients with coronavirus disease 2019 (COVID-19) infection treated with hydroxychloroquine alone or in combination with azithromycin in an intensive care unit. JAMA Cardiol 5:1067

162. Lane JCE, Weaver J, Kostka K et al (2020) Risk of hydroxychloroquine alone and in combination with azithromycin in the treatment of rheumatoid arthritis: a multinational, retrospective study. Lancet Rheumatol 2:e698-e711. https://doi.org/10.1016/ S2665-9913(20)30276-9

163. Saleh M, Gabriels J, Chang D et al (2020) Effect of chloroquine, hydroxychloroquine, and azithromycin on the corrected QT interval in patients with SARS-CoV-2 infection. Circ Arrhythm Electrophysiol 13:e008662. https://doi.org/10.1161/CIRCE P.120.008662

Publisher's Note Springer Nature remains neutral with regard to jurisdictional claims in published maps and institutional affiliations. 